\title{
Genital herpesvirus infection in women attending a venereal diseases clinic
}

\author{
F. E. WILLMOTT AND HELENE J. MAIR \\ From the Royal Infirmary and the Public Health Laboratory, Leicester
}

SUMMARY Routine cervical viral cultures (and cultures from lesions if present) were performed on 2630 female patients attending a venereal diseases clinic over a period of four years Of these patients $96(3.7 \%)$ had genital herpetic infection; of these, $23(24 \%)$ were asymptomatic. The association of herpesvirus with other genital infections is considered, but no increase in the incidence of Neisseria gonorrhoeae, Trichomonas vaginalis, and genital warts was found; there was an increased incidence of Candida albicans. A significantly higher percentage of the patients with herpesvirus took oral contraceptives. The findings are discussed and compared with previous reports.

\section{Introduction}

Interest in genital herpetic infection in women has increased since a possible role in cervical carcinoma has been suggested (Nahmias et al., 1970). The principal mode of transmission is probably by sexual intercourse (Nahmias et al., 1969), and this is reflected in the high incidence found in venereal diseases clinics (Beilby et al., 1968; Morse et al., 1974). This study reports the incidence of genital herpesvirus infection over the period 1973-76 in female patients attending a clinic where virological cultures were taken routinely on all new patients.

\section{Materials and methods}

The study population consisted of 2630 female patients attending the special clinic of the Leicester Royal Infirmary for the first time during the fouryear period, 1973-76. All the patients were examined by one of the authors (FEW).

Swabs for virus isolation were taken routinely from the cervix and from cutaneous lesions if present. These were immersed in transport medium and sent for culture within 24 hours. Routine smears and cultures were also taken for Neisseria gonorrhoeae, Trichomonas vaginalis, and Candida albicans, details of which have been given previously (Willmott, 1975a).

Address for reprints: F. E. Willmott, Royal Infirmary, Leicester LE1 5WW

Received for publication 2 March 1978
TRANSPORT MEDIUM AND VIRUS CULTURE Details of the transport medium and cytomegalovirus culture have been given previously (Willmott, 1975b). Herpesvirus was recognised by its typical cytopathogenic effect. Typing was done by pock size on the chorioallantoic membrane of embryonated eggs.

\section{Results}

Herpesvirus was isolated from $96(3.7 \%)$ out of 2630 patients, cytomegalovirus (CMV) from 157 $(6 \%)$, and adenovirus from two. The yearly incidence of herpesvirus is given in Table 1.

\section{SEASONAL INCIDENCE}

The seasonal incidence is given in the Figure. There was no evidence of seasonal variation $\left(\chi_{11}{ }^{2}=\right.$ $11 \cdot 471, P>0 \cdot 1)$.

\section{AGE RANGE}

The ages of the 96 patients with herpesvirus ranged from 14 to 58 years with a mean of 20.6 years; $65(68 \%)$ of them were under 21 years.

Table 1 Number of female patients with herpesvirus for each year of the study period

\begin{tabular}{llll}
\hline & & \multicolumn{2}{l}{ With herpesvirus } \\
\cline { 3 - 4 } Year & $\begin{array}{l}\text { Total no. of } \\
\text { patients }\end{array}$ & No. & $\%$ \\
\hline 1973 & 510 & 22 & $4 \cdot 4$ \\
1974 & 733 & 23 & $3 \cdot 1$ \\
1975 & 741 & 24 & $3 \cdot 2$ \\
1976 & 646 & 27 & $4 \cdot 2$ \\
Total & 2630 & 96 & $3 \cdot 7$ \\
\hline
\end{tabular}




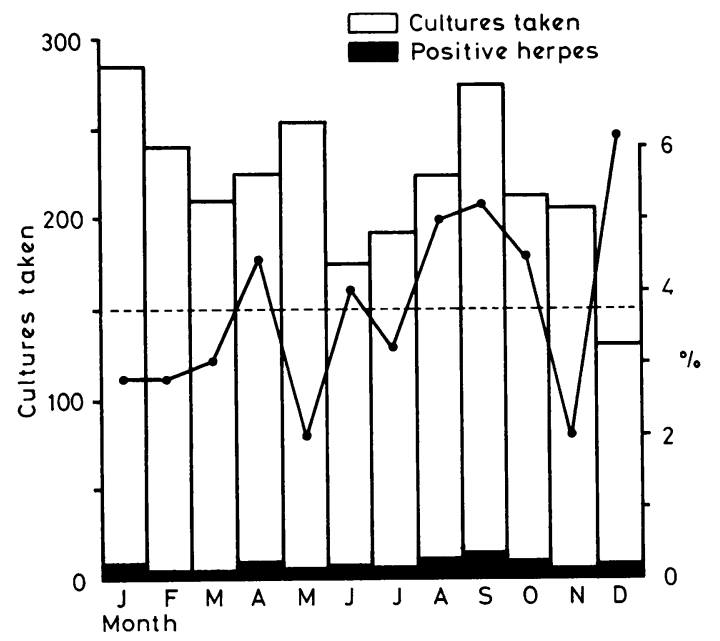

Figure Seasonal incidence of positive cultures for herpesvirus

SIGNS AND SYMPTOMS

Out of the 96 patients, $73(76 \%)$ presented with vulval lesions, while $23(24 \%)$ had no clinical evidence of herpetic infection but positive results from routine cervical cultures. Of the 73 patients with vulval lesions 58 had cervical cultures performed initially (some were too sore for speculum examination), and of these $31(53 \%)$ had positive cultures but only six $(19 \%)$ had typical cervical lesions; $42(57 \%)$ had associated inguinal lymphadenitis. Other sites affected simultaneously with the vulva were the perianal area in five $(7 \%)$, the throat (cultures were taken from patients complaining of a sore throat) in three (4\%), and the lips in two $(3 \%)$. Fourteen $(15 \%)$ of the 96 patients had recurrences within one year.
VIROLOGICAL FINDINGS

Clinical diagnosis of vulval herpes infection was made in 73 patients, of whom $63(86 \%)$ had positive cultures. Seventy-six positive cultures were typed; of these $68(89 \%)$ were type 2 and eight $(11 \%)$ type 1. One patient had a positive type 1 culture on the lip and a positive type 2 culture on the vulva at the same time.

\section{ORAL CONTRACEPTIVES}

Of the 96 patients with herpesvirus $63(66 \%)$ were taking oral contraceptives compared with 1145 $(45 \%)$ out of 2534 without herpesvirus. This is statistically significant $\left(\chi_{1}^{2}=19 \cdot 775, \mathrm{p}<0.001\right)$. Further details concerning contraception are shown in Table 2.

\section{CONSORTS}

Of the 38 male consorts examined $12(32 \%)$ had herpetic infection. All 12 had typical penile herpetic lesions; of these 11 had cultures taken, and nine gave positive results for herpesvirus.

\section{ASSOCIATED INFECTIONS}

No difference in the isolation rate of $N$. gonorrhoeae, $T$. vaginalis, and genital warts was found in the patients with herpesvirus compared with those without (Table 3). There was, however, a significant difference in Candida isolation between the patients with and without herpes $\left(\chi_{1}{ }^{2} 14.901, \mathrm{P}<0.001\right)$.

Cytomegalovirus (CMV) was isolated from the cervix of two patients who at the same time had culture-positive herpetic lesions on the vulva. In seven other patients CMV was isolated subsequently, and of these two had CMV mononucleosis. There was no difference in the incidence of CMV between the patients with and without herpesvirus.

Table 2 Details of contraceptive methods in patients with and without herpesvirus

\begin{tabular}{|c|c|c|c|c|c|c|c|c|c|c|}
\hline & \multicolumn{2}{|c|}{ Oral contraceptive } & \multicolumn{2}{|c|}{ No oral contraceptive } & \multicolumn{2}{|c|}{$I U C D$} & \multicolumn{2}{|c|}{ Pregnant } & \multicolumn{2}{|l|}{ Total } \\
\hline & No. & $\%$ & No. & $\%$ & No. & $\%$ & No. & $\%$ & No. & $\%$ \\
\hline $\begin{array}{l}\text { With herpesvirus } \\
\text { Without herpesvirus }\end{array}$ & $\begin{array}{r}63 \\
1082\end{array}$ & $5 \cdot 5$ & $\begin{array}{r}28 \\
1234\end{array}$ & $2 \cdot 2$ & $\begin{array}{r}0 \\
86\end{array}$ & 0 & $\begin{array}{r}5 \\
132\end{array}$ & $3 \cdot 6$ & $\begin{array}{r}96 \\
2534\end{array}$ & $3 \cdot 7$ \\
\hline
\end{tabular}

Table 3 Number of patients with other infections associated with herpesvirus

\begin{tabular}{|c|c|c|c|c|c|c|c|c|c|c|}
\hline & \multicolumn{2}{|c|}{ Gonorrhoea } & \multicolumn{2}{|c|}{ Trichomonas } & \multicolumn{2}{|c|}{ Warts } & \multicolumn{4}{|c|}{ Candidosis } \\
\hline & No. & $\%$ & No. & $\%$ & No. & $\%$ & No. & & & $\%$ \\
\hline $\begin{array}{l}\text { With herpesvirus } \\
\text { Without heresvirus }\end{array}$ & $\begin{array}{r}22 \\
610\end{array}$ & $\begin{array}{l}23 \\
24\end{array}$ & $\begin{array}{r}23 \\
496\end{array}$ & $\begin{array}{l}24 \\
20\end{array}$ & $\begin{array}{r}10 \\
239\end{array}$ & $\begin{array}{r}10 \\
9\end{array}$ & $\begin{array}{r}51 \\
862\end{array}$ & & & $\begin{array}{l}53 \\
34\end{array}$ \\
\hline
\end{tabular}




\section{Discussion}

The incidence in our study of $3.7 \%$ compares with that of $3.5 \%$ (Nahmias et al., 1969) and $3.8 \%$ (Beilby et al., 1968) in other studies. The association of vulval and cervical herpesvirus has been reported by Josey et al. (1968); we found an incidence of $53 \%$. Asymptomatic cervical herpes was first described by Naib et al. (1966); we found an incidence of $24 \%$ in patients with herpesvirus. In our study $86 \%$ of cultures were positive compared with $74 \%$ in the study by Nahmias et al. (1969) and $47 \%$ in that by Amstey (1975). Type 2 herpesvirus accounted for $89 \%$ of the isolates, which is consistent with the findings of Nahmias et al. (1969) and Amstey (1975), who reported $96 \%$ and $90 \%$ respectively.

The high number of patients taking oral contraceptives in the group with herpesvirus has not previously been reported, although it has been reported in patients with CMV infections (Willmott, 1975b). It is possible that the high incidence is thus partly due to the lack of a mechanical barrier, which is afforded by the sheath.

Only $32 \%$ of the male consorts who were examined had herpetic infection. This suggests a high incidence of asymptomatic herpetic infection in men, as reported by Centinfanto et al. (1972) but not substantiated by Traub et al. (1973).

There was no increased incidence of $N$. gonorrhoeae in the herpetic group which agrees with the report of Nahmias et al. (1973). Similarly there was no increased incidence of $T$. vaginalis and genital warts, which contrasts with the findings of Rawls et al. (1971). The increased incidence of candidosis in the group with herpesvirus has not been reported previously, but it is of practical importance in the treatment of herpetic vulvitis.
A recent report on the simultaneous isolation of CMV and herpesvirus from the same patient (Manuel and Embil, 1977) suggests this may be a common association. Only two such patients were found in this series, and the subsequent isolation of CMV was no higher in the group of patients with herpesvirus.

\section{References}

Amstey, M. S. (1975). Genital herpesvirus infection. Clinical Obstetrics and Gynaecology, 18, 89-100.

Beilby, J. O. W., Cameron, C. H., Catterall, R. D., and Davidson, D. (1968). Herpes virus hominis infection of the cervix associated with gonorrhoea. Lancet, 1, 1065-6.

Centinfanto, Y. M., Drylie, D. M., Deardowff, S. L., and Kaufman, H. (1972). Herpesvirus type 2 in the male genitourinary tract. Science, 178, 318-9.

Josey, W., Nahmias, A., and Naib, Z. (1968). Genital infection with type 2 herpesvirus hominis. American Journal of Obstetrics and Gynecology, 101, 718-729.

Manuel, F. R., and Embil, J. A. (1977). Simultaneous isolation of herpesvirus hominis type 2 and cytomegalovirus from the genital tract of a woman. Sexually Transmitted Diseases, 4, 18-19.

Morse, A., Coleman, D. V., and Gardner, S. D. (1974). An evaluation of cytology in the diagnosis of herpes simplex virus infection and cytomegalovirus infection of the cervix uteri. Journal of Obstetrics and Gynaecology of the British Commonwealth, 81, 393-398.

Nahmias, A. J., Dowdle, W. R., Naib, Z. M., Josey, W. E., McClone, D., and Domescik, G. (1969). Genital infection with type 2 herpesvirus hominis. British Journal of Venereal Diseases, 45, 294-298.

Nahmias, A., Josey, W., Naib, Z., Luce, C., and Duffey, C. (1970). Antibodies to herpesvirus hominis types 1 and 2 in humans. American Journal of Epidemiology, 91, 539-552.

Nahmias, A. J., Von Reyn, C. F., Josey, W. E., Naib, Z. M., and Hutton, R. D. (1973). Genital herpes simplex virus infection and gonorrhoea. British Journal of Venereal Diseases, 49, 306-309.

Naib, Z., Nahmias, A., and Josey, W. (1966). Cytology and histopathology of cervical herpes simplex infection. Cancer, 19, 1026-31.

Rawls, W. E., Gardner, H. A., Flanders, R. W., Lowry, S. P., Kaufman, R. H., and Melinck, J. L. (1971). Genital herpes in two social groups. American Journal of Obstetrics and Gynecology, 110, 682-689.

Traub, R. G., Madden, D. L., Fuccillo, D. A., and McLean, T. W. (1973). Letter, New England Journal of Medicine, 289, 697.

Willmott, F. E. (1975a). Genital yeasts in female patients attending a VD clinic. British Journal of Venereal Diseases, 51, 119-122.

Willmott, F. E. (1975b). Cytomegalovirus in female patients attending a VD clinic. British Journal of Venereal Diseases, 51, 278-280. 